\title{
Construindo cidadania: o projeto requalificação da Feira de São Joaquim em Salvador
}

\author{
Valdemar de Assis Lima* \\ Elison Antonio Paim**
}

\begin{abstract}
Resumo
Relatamos o levantamento para a requalificação da feira de São Joaquim em Salvador - BA. As atividades foram desenvolvidas em 2008 por uma equipe multidisciplinar na forma de convênio firmado entre a Secretaria de Cultura do Estado da Bahia (Secult) e o Governo Federal, pelo Ministério da Cultura, supervisionada pelo Instituto do Patrimônio Histórico e Artístico Nacional (IPHAN). A pesquisa apoiou-se principalmente no diálogo com os feirantes e frequentadores, bem como em documentos diversos. Buscou-se registrar os saberes e fazeres realizados valendo-se do binômio cultura/educação na valorização do ser humano fundamentados na busca da cidadania cultural para o exercício crítico e responsável nos usos e apropriações daquele patrimônio cultural.

Palavras-Chave: Alfabetização cultural; construção de cidadania; educação para o patrimônio; Feira de São Joaquim.
\end{abstract}

\section{Building citizenship: the requalification project of São Joaquim's Fair in Salvador}

\begin{abstract}
This paper consists in a survey to the requalification of São Joaquim's Fair in Salvador - BA. The activities were developed in 2008 by a multidisciplinary team through an agreement between Bahia's State Culture secretary (Secretaria de Cultura do Estado da Bahia - Secult) and the Federal Government, through the Ministry of Culture, supervised by the National Institute of Historic and Artistic Heritage (Instituto do Patrimônio Histórico e Artístico Nacional - IPHAN). The research leaned mainly in the dialog with the fair dealers and goers, and assorted documents as well. It sought to register the knowledges and practices performed using the binomial culture/education in valorization of the human being, based in the search of cultural citizenship to the critical and responsible exercise in the uses and appropriations of that cultural patrimony.

Keywords: Cultural alphabetizing; Citizenship construction; Education to patrimony; São Joaquim's Fair
\end{abstract}

A cultura nacional não é o folclore em que um populismo abstrato acreditou descobrir a verdade do povo. Ela não é uma massa sedimentada de gestos puros, isto é, cada vez menos correlatos à realidade presente do povo. A cultura nacional é o conjunto dos esforços feitos por um povo no plano do pensamento para descrever, justificar e cantar a ação através da qual o povo se constitui e se mantém. A cultura nacional, nos países subdesenvolvidos, deve pois, situar-se no próprio centro da luta de libertação que esses países travam (FANON, 2005, p. 268).

É profundamente inspirados nas provocações para a descolonização de nossas mentes feitas pelo grande pensador martinicano Frantz Fanon, especialmente nos livros $O s$ condenados da terra (2005) e Pele Negra, máscaras brancas (2008), nos quais nos põe em choque com a forma eurocêntrica de fazer ciência e tratar o patrimônio em nosso país, que ousamos apresentar aqui uma experiência vivida por uma equipe interdisciplinar composta por uma antropóloga, um

\footnotetext{
*Endereço Eletrônico: poesiadomar@gmail.com

***Endereço Eletrônico: elison0406@ gmail.com
}

arquiteto, um historiador e dois museólogos com a missão de desenvolver o projeto de requalificação da Feira de São Joaquim.

Em julho de 2008 foi constituído um convênio entre a Secretaria de Cultura do Estado da Bahia (Secult) e o Governo Federal por meio do Ministério da Cultura, que disponibilizou recursos para a elaboração do Projeto de Requalificação da Feira de São Joaquim (PRFSJ) - $1^{\mathrm{a}}$ etapa, tendo como responsável pela supervisão do processo e gestão dos recursos o Instituto do Patrimônio Histórico e Artístico Cultural.

O nome Feira de São Joaquim é uma referência à igreja e ao Colégio dos Órfãos de São Joaquim - ambos pertencentes à Ordem dos Jesuítas - localizados no bairro do Comércio, em frente à Feira. Fundada há mais de 40 anos, é uma das maiores feiras livres do Brasil, com um espaço de $60 \mathrm{mil} \mathrm{m}^{2}$ onde se distribuem os cerca de 7.500 feirantes, entre comerciantes fixos e vendedores avulsos. A FSJ tem mais de 4 mil boxes onde são vendidos alimentos típicos do estado da Bahia e de outros estados da região Nordeste do Brasil. 
Gerando emprego e renda para mais de $40 \mathrm{~m}$ mil pessoas, essa feira baiana está em processo de obtenção do título de patrimônio cultural imaterial do Brasil, conferido pelo Instituto do Patrimônio Histórico e Artístico Nacional (IPHAN), a exemplo de outros lugares culturais.

O PRFSJ é voltado, justamente, para a preservação e desenvolvimento da sustentabilidade da FSJ, por meio da estruturação, em diálogo com os feirantes, de um modelo de gestão contemplando os aspectos: administrativo, fiscal, comercial urbanístico, socioambiental, cultural e turístico, com vistas ao fortalecimento das dinâmicas características da Feira.

A partir do estudo de caso que é a experiência de atuação de um grupo de trabalho formado por pesquisadores de diferentes áreas no PRFSJ, fizemos uma reflexão sobre o patrimônio cultural de natureza imaterial no ensino médio e fundamental das escolas públicas da cidade de Salvador, visando a alfabetização cultural e a construção da cidadania a partir do uso social da memória cultural.

Numa perspectiva de identificação e valorização do Patrimônio cultural local, foram trabalhados os aspectos culturais imateriais da Feira de São Joaquim - as trocas simbólicas, os saberes e fazeres, as possibilidades sensoriais, a memória cultural dos feirantes, clientes e demais pessoas que a frequentam - no ensejo do PRFSJ.

E é no contexto dessa análise dos caracteres tangíveis e intangíveis que adejam o lugar cultural que é a feira, que o PRFSJ se ocupou em fomentar junto aos principais órgãos e instituições de salvaguarda da cultura o desenvolvimento das bases legais, administrativas, técnicas, tecnológicas e políticas para a preservação dessa dimensão do patrimônio cultural.

O trabalho desenvolvido pelo grupo de pesquisadores na FSJ foi estruturado dentro da proposta do Projeto de Requalificação, onde os diferentes profissionais foram organizados em Grupos de Trabalho (GTs) dentre os quais o GT Sociocultural, cuja equipe era composta pela antropóloga Anita Gil; pelo historiador Gilmar Gusmão; pelo então estudante do curso de Museologia, Leonardo Batista; pelo museólogo Valdemar Lima (que atuou como coordenador técnico do referido GT) e o museólogo e arquiteto Julio Abe Wakahara (coordenador executivo deste GT).

A pesquisa estruturada pela equipe transdisciplinar supracitada elaborou um inventário dos saberes e fazeres da FSJ, ao tempo em que fez o levantamento de publicações, imagens, material gráfico, trabalhos acadêmicos, documentos históricos, entrevistas e visitas técnicas (na FSJ e nos municípios responsáveis pelo fornecimento de produtos revendidos nessa feira) para colher o maior número possível de informações que subsidiasse o trabalho a ser desenvolvido pela equipe.

As primeiras feiras no Brasil remontam aos primórdios do período colonial. Com a ocupação das áreas interioranas do território brasileiro, a colonização do Brasil se efetiva. De certo, a economia pecuária foi um dos principais elementos - se não o principal - que impulsionou esse processo, uma vez que, para dimanar o gado do sertão às vilas litorâneas, foram abertos caminhos que tecem novas estradas no interior. $\mathrm{O}$ fomento do comércio bovino, bem como outras atividades lucrativas, tais como a venda de produtos agrícolas, foi decisivo para a estruturação da economia nordestina, além de corroborar para a fixação definitiva de populações nas áreas do agreste e do sertão, influenciando a economia e a sociedade, imprimindo uma nova dinâmica de intercâmbio entre o litoral e o interior.

Há referências às feiras no regimento que D. João III enviou ao Governo Geral da colônia, ordenando a realização de feiras semanais. Segundo Mott (1975), a principal razão que motivou a ordem real para a realização de mais feiras na colônia, não era a preocupação em suprir o abastecimento alimentício da população, antes, promover o direcionamento da produção regional para a exportação, de forma sistemática.

Não obstante as pretensões do Rei, as feiras não se estabeleceram como almejado pela Coroa, uma vez que a economia do engenho não produzia excedente. $\mathrm{O}$ suprimento de alimentos produzidos não era compatibilizado com o crescimento populacional. Como consequência, houve insuficiência de alimentos para os crescentes núcleos populacionais das vilas e cidades.

Uma das prováveis explicações para essa escassez no abastecimento talvez seja o modelo do sistema socioeconômico implantado pela Coroa, cujo objetivo era a exploração das riquezas naturais visando à exportação. Esse sistema baseava-se em dois principais suportes, a saber, a cultura do engenho, que era de autossubsistência, e as poucas vilas, que funcionavam como porto de embarque da produção açucareira (MOTT, 1975).

A cidade de Salvador e o Recôncavo ${ }^{1}$ eram os dois extremos de rotas comerciais. As 
mercadorias compradas diretamente no Recôncavo pelos proprietários das barracas eram vendidas nas feiras e nos mercados de Salvador. Tal comércio era feito diariamente por centenas de saveiros, que traziam do Recôncavo produtos da indústria extrativista, como a piaçava, a lenha, a farinha e as madeiras. Em Salvador, os saveiros atracavam no cais de Cairu junto à rampa do Mercado Modelo, na Feira de Água de Meninos $^{2}$, na Preguiça, nos bairros da Ribeira e do Bonfim e levavam, dentre outros objetos, tecidos e utensílios de uso doméstico para os portos das cidades baianas de Santo Amaro da Purificação, São Francisco do Conde, Salinas das Margaridas, Aratuípe, Maragojipe Cachoeira e São Félix.

A cidade baixa foi até o final do séc. XIX a área da cidade do Salvador onde se concentravam, majoritariamente, as atividades comerciais, tanto as relacionadas ao porto, quanto as ligadas ao comércio varejista, como feiras e mercados, além de vendedores ambulantes e camelôs.

No decorrer de mais de cinquenta anos muitas mudanças foram ocorrendo nas feiras de Salvador. Algumas feiras desapareceram, outras foram reduzidas ou mudaram de lugar e de estrutura de funcionamento. A Feira da Barra e a Feira do Porto da Lenha já não existem mais. A Feira do Largo Dois de Julho se reduziu praticamente à venda de flores. A Feira de Sete Portas mudou sua estrutura física e é hoje uma feira coberta.

Seja em obras literárias, nas artes plásticas ou nas produções cinematográficas, a Feira de São Joaquim tem sido representada como indelével constituinte, tanto do tecido sociocultural, quanto do imaginário popular do povo baiano.

Proveniente de outras duas feiras que funcionavam na região da Cidade Baixa, no bairro do Comércio, em Salvador, a FSJ é também um espaço de resistência dos afrodescendentes. A Feira do Sete funcionava em um antigo galpão na região do bairro, no cais das docas e, devido a seu crescimento, foi ocupando uma área territorial cada vez maior, chegando a atingir a região de Água de Meninos, passando a ser conhecida não mais como a Feira do Sete, e sim como Feira de Água de Meninos. Em 1964, ocorreu um incêndio criminoso na Feira e, posteriormente a esse acontecimento, foi "criada" a Feira de São Joaquim.

É importante ressaltar que a Feira sempre foi vista de forma depreciativa pela elite racista da cidade do Salvador. Jornais de grande circulação, desde a década de 1960, estampavam manchetes preconceituosas e discriminatórias ressaltando aspectos negativos como a sujeira, e uma suposta falta de ordenamento, atribuindo culpabilidade aos feirantes e ao povo humilde que ali buscava mercadorias e serviços por um preço condizente com seu parco poder aquisitivo. O que nos chama atenção é que nesses discursos pejorativos, evidencia-se a intenção de atribuir um caráter negativamente valorado ao negro, associando-o à pobreza, sujeira, baderna, doenças e ao mau cheiro, gritantemente frisados nas matérias tendenciosas que ainda se observa, vez por outra, em reportagens jornalísticas.

O patrimônio cultural de um povo são todos os bens culturais, portadores de valores simbólicos, que podem ser transmitidos a gerações futuras. Constitui-se como um sistema de representações que confere identidade e orientação a um determinado agrupamento social, a fim de que esse possa se reconhecer como comunidade, estimulando o exercício da cidadania, por meio de um sentimento de pertencimento e de continuidade histórica.

Dessa maneira, a integração entre a educação escolar e a feira, enquanto espaço de expressão da cultura é uma tentativa de preservar e dinamizar um saber popular, elaborado ao longo de muitos anos, transmitido de geração em geração e que coexiste com o processo histórico-cultural da Bahia e, por seu turno, sensibilizar os jovens para assumirem uma cidadania responsável, a partir da compreensão do que é patrimônio cultural e qual é seu papel na formação holística do ser humano.

Ao analisarmos o advento da globalização, podemos perceber que houve uma dramática interferência em todas as formas de organização social, econômica, política e cultural. O rápido desenvolvimento das sociedades contemporâneas impõe mutações culturais dramáticas que ameaçam a preservação dos patrimônios culturais locais.

Considerando que os bens culturais compreendem o ambiente e toda a produção de natureza material e imaterial, a constituição da identidade cultural do povo envolve a fruição ${ }^{3}$ e a valorização desses bens culturais. A expressão musical, a memória oral, e demais elementos caracterizadores de sua civilização, além da produção artística, material ritual, mobiliário e objetos utilitários, os imóveis (compreendendo também seu entorno) são eivados de signos e símbolos cuja decodificação e internalização por parte das pessoas é fundamental, na construção dessa dada identidade cultural.

Durante a Convenção para a Salvaguarda do 
Patrimônio Cultural Imaterial, realizada em 2003, em Paris, a UNESCO definiu o patrimônio cultural imaterial - e seus elementos constitutivos - como sendo uma dimensão do patrimônio cultural que abrange todas as práticas, representações, expressões, conhecimentos, técnicas e instrumentos, artefatos e lugares que lhes são associados, nos quais as comunidades e as pessoas indentificam como integrantes de seu patrimônio cultural e lhes instila o sentimento de pertencimento. Ainda segundo a mesma conveção, a cultura imaterial, transmitida às gerações subsequentes, "é constantemente recriado[a] pelas comunidades e grupos em função do seu ambiente, de sua interação com a natureza e de sua história, gerando um sentimento de identidade e continuidade e contribuindo assim promover o respeito à diversidade cultural e à criativa humana" (UNESCO, 2003).

$\mathrm{O}$ bem cultural de natureza imaterial pode $\mathrm{e}$ deve ser tocado pelas pessoas que o elegem, no sentido de ser vivenciado, experimentado e experienciado perto de todos os sentidos humanos. Todas as produções culturais são passíveis de serem apropriadas pelo agrupamento social que o reconhece e o legitima como identitário para a sua cultura.

A consciência da diversidade do patrimônio cultural brasileiro e de que muitas de suas expressões são de natureza imaterial já estavam presentes nos estudos de Mário de Andrade e Luis da Câmara Cascudo, na década de 1920, cuja fundamentação teórica foi basilar para a criação de um instrumento legal que formalizasse $o$ reconhecimento e adequada preservação desses valores.

É digno de nota que, na conclusão do dossiê final das atividades da Comissão e do Grupo de Trabalho Patrimônio Imaterial do Ministério da Cultura $^{4}$, foi constatado por este grupo que "o patrimônio imaterial tem sido conceitualmente associado às criações e expressões da cultura tradicional e popular, notadamente aquelas transmitidas oralmente" (BRASIL, 2006). Contudo, o grupo também se referia às tentativas de superação da divergência que ainda há entre patrimônio material e imaterial, indicando que ambos os aspectos precisam ser considerados simultaneamente, além de se valorizar aqueles que detêm a tradição e de se estudar as circunstâncias nas quais se desenvolve o processo de transmissão do conhecimento por eles adquirida.

Assim, com o Decreto $\mathrm{n}^{\circ} 3.551$ de 4 de agosto de $2000^{5}$, o Governo Federal instituiu o registro dos bens de natureza imaterial com vistas à preservação dos elementos da cultura aos quais não se podia aplicar o instrumento de salvaguarda direcionado para a cultura material. O Instituto do Patrimônio Histórico e Artístico Nacional (IPHAN) é o órgão responsável pela efetuação desses registros. Nesse contexto histórico, a política cultural brasileira oficialmente passou a adotar o conceito de patrimônio imaterial, outrora denominado patrimônio intangível.

É importante ressaltar que, no bojo das ações desenvolvidas pela Política Nacional de Museus, o Ministério da Cultura, na gestão do então ministro Gilberto Gil Moreira, lançou o Programa Nacional do Patrimônio Imaterial para fomentar a identificação, o reconhecimento, a salvaguarda e a promoção da dimensão imaterial do patrimônio cultural brasileiro, valorizando e incentivando grupos detentores, produtores e dinamizadores do patrimônio imaterial.

Apropriando-se dos fundamentos propostos pela UNESCO no Conselho Internacional para Monumentos e Sítios (ICOMOS) que orientam sobre o tombamento dos Talentos Humanos Vivos e das expressões imateriais da cultura, há uma grande tendência nacional e internacional sobre o reconhecimento do valor do patrimônio imaterial.

É sob o signo dessa dimensão de patrimônio cultural que problematiza a professora Heloísa Helena F. G. da Costa $(2013, \mathrm{~s} / \mathrm{p})^{6}$ :

Nesse sentido, considero pertinente reabrir a questão sobre o conceito ampliado de patrimônio e sobre as características que identificam aquilo que deve ser considerado patrimônio. Um monumento, uma casa? Uma estória, um ritual, uma lenda? Um rio, uma fonte, um bosque? [...]. O que se faz necessário para que um bem cultural seja reconhecido e tombado como patrimônio? Durante muitos séculos, pensou-se que o valor era auferido por critérios estéticos, artísticos, históricos, de raridade, de genialidade, entre outros. Mas a noção ampliada de patrimônio estabelecida na Declaração de Caracas, em 1992 que afirma "o patrimônio cultural de uma nação, região ou de uma comunidade é composto de todas as expressões materiais e espirituais que o constituem, incluindo o meio ambiente natural", vem modificando a reflexão e o olhar de descoberta que se debruça sobre os elementos simbólicos que dão testemunho do fazer humano. 
No tocante à valorização do caráter humano, no processo de registro do bem cultural imaterial, a equipe de técnicos que compunham o Grupo de Trabalho Sociocultural (GTSC) do Projeto de Requalificação da Feira de São Joaquim (PRFSJ), iniciativa que envolveu as esferas municipal, estadual e federal, desenvolveu um levantamento dos tesouros humanos dessa feira: as histórias, memórias e curiosidades de pessoas relevantes no contexto histórico, entre as quais, as detentoras de notório saber, visando à salvaguarda e preservação da memória social da gente cujas histórias de vida amalgamam-se e coerem com a história da Feira.

Pensando em atender às demandas oriundas dos questionamentos da própria comunidade da Feira e todos os interessados por ela, o Grupo de Trabalho Sociocultural elencou quatro etapas: a primeira, selecionando elementos considerados importantes à Feira de São Joaquim, após um processo de exploração e diagnóstico; a segunda, a ordenação desses elementos; a terceira, a interpretação sociocultural desses, envolvendo diversos discursos (dos informantes, dos poderes políticos em todos os seus níveis, e os grupos sociais) e a quarta, a exposição museológica das informações recolhidas.

Nesse respeito, o PRFSJ enfatiza a necessidade de valorização de um importante símbolo identitário da diversidade cultural afrobrasileira, cujas diversas matrizes culturais que a constituem, lhe consagram como uma das mais diversificadas culturas mundiais.

A cultura popular brasileira é a expressão genuína da identidade do seu povo e, portanto, precisa de iniciativas preservacionistas que garantam a sua sobrevivência de geração a geração enquanto patrimônio identitário da sua vasta diversidade.Com efeito, o patrimônio cultural a ser preservado é o bem material e/ou imaterial que simbolicamente reflete a produção cultural de uma sociedade específica e, dessa forma, aufere-se que o verdadeiro patrimônio é a memória dos seres humanos enquanto atores sociais, uma vez que 'um monumento sem identificação precisa e sem legitimação será considerado patrimônio para quem?' (COSTA, 2002).

Tanto os registros históricos quanto os memoriais, assim, mediante narrativas oficiais e coletivas, advindas dos esforços de recuperação da memória social, os registros da memória afetiva e/ou traumática, são suportes somenos fundamentais para o trabalho do especialista de identificar toda a riqueza do patrimônio cultural imaterial.

Transmitido de geração em geração, o patrimônio cultural de natureza imaterial, dinâmico por natureza, é recriado pelos agrupamentos sociais em função de seu ambiente, de sua interação com a natureza e de sua história, o que gera um sentimento de pertencimento e continuidade, contribuindo assim para promover o respeito e a valorização da diversidade cultural, bem como o fomento e a preservação da herança cultural.

A cultura popular é uma expressão da identidade do povo brasileiro e, portanto, precisa de iniciativas preservacionistas que garantam a sua sobrevivência enquanto patrimônio identitário da sua vasta diversidade.

No contexto da cultura popular, o bem cultural imaterial é uma importante vertente da grande diversidade de bens culturais que incluem espaços culturais, manifestações linguísticas, artísticas, litúrgicas e festivas peculiares do Brasil. É na cultura popular que estão indelevelmente presentes os saberes e fazeres, as formas de expressão, as celebrações e os lugares nos quais se dão as trocas simbólicas que constituem o patrimônio cultural brasileiro.

Nesse sentido, é condição sine qua non para a salvaguarda da memória cultural, a efetivação de projetos e ações que se proponham a identificar, documentar esse patrimônio imaterial em sua diversidade e variedade tipológica, registrando suas peculiaridades, especificidades, consubstanciações e dinâmicas; fomentando a socialização do acesso a esse, além de estimular o seu uso sustentável, para as gerações futuras e para a melhoria da qualidade de vida de seus produtores e detentores. Feito isso, poder-se-á, com efeito, estruturar políticas pedagógicas que se valham desses subsídios e formulem práticas de ensino-aprendizado através do binômio educação-cultura.

$\mathrm{O}$ pesquisador Miguel Santos afirma que as feiras "constituem importantes fenômenos para entender a organização do espaço urbano regional, e, no entanto, são pouco estudadas" (2002, p. 53). Partindo dessa premissa, a partir das pesquisas, entrevistas e visitas de campo na Feira de São Joaquim, a equipe de pesquisadores do GT Sociocultural pode auferir que esse lugar cultural é um legítimo repositório da cultura brasileira uma vez que se trata de um importante referencial para a identidade e a memória cultural do país. Mas, apesar dessa riqueza latente, ainda é incipiente a quantidade de propostas de trabalho que valorizem a 
FSJ como espaço no qual podem ser desenvolvidas pesquisas e práticas pedagógicas pelo bem da salvaguarda da identidade cultural.

Entendendo que o ser humano tem papel determinante no processo de criação e recriação da cultura, faz-se necessário que as ações educativoculturais implementadas junto à FSJ corroborem a prevalência do caráter humano no cerne do contexto com vistas a acentuar a importância da Feira e, principalmente do feirante, na construção e reconstrução de elementos culturais fundamentais para que a FSJ continue sendo um centro agregador de bens culturais e ao mesmo tempo um bem cultural legitimado pela diversidade de pessoas que a frequentam. É justamente a preservação dessa dinâmica que corrobora para a própria preservação da FSJ, como patrimônio cultural brasileiro.

As histórias, memórias, curiosidades, saberes e fazeres dos tesouros humanos da FSJ; as trocas simbólicas; as estratégias de comunicação; a linguagem estética peculiar e recursos visuais; a setorização de produtos, sua disposição e itinerários de localização; as rotas dos produtos tradicionais que chegam à FSJ e nela circulam - sua produção, origem, significados, usos, costumes; os objetos rituais, as ervas, folhas, cascas, sementes e raízes compõem um acervo diversificado, repleto de signos e símbolos que caracterizam a própria diversidade cultural brasileira, por seu valor imaterial, e como tal, exigem uma leitura específica.

Em se tratando de religiosidade afrobrasileira, é importante ressaltar que os terreiros de Candomblé, Caboclo e Umbanda (só pra citar alguns) de outros estados como Rio de Janeiro, São Paulo e de outros países como França, Portugal, Itália e Angola, adquirem seus produtos ritualísticos na FSJ, uma vez que, para as religiões de matriz cultural africana, o axé - elemento legitimador e consagrador das práticas ritualístico-religiosas dessas denominações religiosas - é encontrado apenas em Salvador, notadamente na FSJ. Tal exclusivismo sagrado eleva a FSJ, qual lugar de memória cultural, à categoria de importante centro de referência da cultura e religiosidade afrobrasileira em nível internacional.

Na FSJ há uma infinidade de produtos e alimentos relacionados à cultura afro-brasileira, o que faz com que à Feira afluam, todos os dias, milhares de baianas de acarajé, adeptos das religiões de matriz cultural africana e grande público oriundo de diversos países, que vem em busca desses produtos. Igualmente, não percamos de vista o fato de que bens culturais como o Ofício das Baianas de
Acarajé, a Capoeira, e festas populares do calendário festivo afro-luso-brasileiro, dependem da FSJ para sua sobrevivência. As tradicionais contas do Afoxé Filhos de Gandhi, o azeite de dendê, as pimentas, o agdá, panelas e utensílios feitos de barro, infindas tipologias de produtos e serviços. Enfim, os elementos formadores e constituintes da identidade cultural baiana e, portanto, brasileira, são encontrados, em profusão, na FSJ.

Fé e festa; sagrado e profano se encontram na FSJ que, não somente fornece produtos e serviços para os festejos, rezas, lavagens e procissões tradicionais da cultura baiana como também, na própria Feira, essas diversas expressões culturais se dão, como a famosa Feijoada dos Feirantes (ou Feijoada de Ogum), ${ }^{7}$ no mês de outubro e, no mês de setembro, o não menos famoso Caruru dos Feirantes, entre outras expressões. Além disso, bares e restaurantes funcionam como uma espécie de extensão das lavagens do Bomfim, Conceição da Praia e Bom Jesus dos Navegantes ${ }^{8}$.

A Feira é, sobretudo, um lugar de memória e as trocas simbólicas, a transmissão de saberes e fazeres de geração a geração que ali se dão, de forma profusa e contínua, não somente no comércio, como também nas festas e ritos, na música, nos mitos e lendas, nas conversas, na culinária, concorrem para que esse espaço/objeto cultural seja considerado e valorizado como um repositório cultural.

O contato entre os feirantes e os clientes e demais pessoas que afluem à FSJ, ultrapassa o interesse comercial, uma vez que nessa dialética são estabelecidas relações de confiança, compadrio, amizade que atravessam gerações. A FSJ precisa ser entendida, portanto, não apenas como um lugar de comércio, mas como um espaço de interação, sociabilidade, afetividade, trocas simbólicas e, principalmente, de repositório de tradições, mantidas e ressignificados na dinâmica sóciohistórica, que constituem a vida urbana.

$\mathrm{O}$ registro da Feira de São Joaquim como patrimônio cultural brasileiro enfatiza a necessidade de valorização da diversidade cultural brasileira cujas diversas matrizes culturais constituintes lhe consagram como uma das mais sofisticadas culturas mundiais.

O inventário do acervo da FSJ, cujos bens constituintes, em grande parte, foram elencados pela comunidade local, quando das entrevistas e pesquisas realizadas pelo grupo de técnicos do Grupo de Trabalho Sociocultural (GTSC) do PRFSJ, subsidiou a abordagem histórica, 
antropológica e museológica utilizada que, por sua vez, revelou os significados dos elementos constituintes da identidade cultural baiana, presentes no tecido social dessa feira e incorporados ao imaginário popular brasileiro.

Tal estudo aprofundado, que desenvolvemos sobre o lugar, revelou as transformações que a FSJ sofreu ao longo dos anos e nos permitiu perceber mais claramente as relações ali estabelecidas, bem como as permanências e alterações no seu ambiente.

Deveras, com o advento da globalização, a centralização da economia e do poder político sob o controle das potencias hegemônicas facilitaram a atuação das transnacionais e do processo de desenvolvimento tecnológico que interferiram nas práticas cotidianas das sociedades locais. Essas modificações foram resultado da crescente difusão de informações, imagens e mercadorias que levaram a uma homogeneização de lugares, desejos, pensamentos e estilos de vida (AUGÈ, 1994). O espaço urbano tornou-se alvo de ações dessa dinâmica global. Portanto, torna-se necessária a valorização das particularidades dos agrupamentos sociais, para manter a integridade das identidades culturais dos grupos.

São inúmeros os predicados que consagram a FSJ como lugar identitário, relacional e histórico", servindo, portanto, como referencial para a salvaguarda da memória e cultura local. Os produtos tradicionais da cultura baiana e brasileira, ali encontrados, agregam valores simbólicos e representativos por reforçar práticas sociais transmitidas de geração em geração. São esses mesmos produtos que demonstram a relação da FSJ com outros espaços (o doméstico, os municípios baianos e com outros estados), expressam modos de vida própios da cultura local, estabelecidos nas relações de compra e venda, na culinária, no consumo, na religiosidade, na familiaridade, no lazer, no trabalho, na afetividade, entre outros aspectos da vida social.

Preservar a Feira, além de manter viva a heterogeneidade cultural, reafirma um movimento de resistência que se contrapõe à força esmagadora da tendência homogeneizante do processo de globalização.

A disposição e comercialização dos produtos tradicionais, por exemplo, na FSJ não obdecem às exigências do capitalismo contemporâneo. Embora, pesos e medidas tenham alcançado um grau de precisão que posibilitariam o aumento do lucro, no espaço da feira essa padronização sofre um processo de relativização e os laços estritamente comerciais absorvem outras características ao ato de compar e vender.

Selecionamos alguns elementos do acervo cultural da FSJ, abordando questões de caráter histórico, antropológico e museológico relacionadas ao significado dessa feira tradicional para o imaginário popular, no sentido de sensibilizar a comunidade que frequenta e trabalha na Feira, para questões relacionadas à preservação da herança cultural, valorização da qualidade socioambiental e a apropriação da Feira por parte da comunidade, que a legitima enquanto patrimônio cultural.

Tendo em vista essa dinâmica antropológico-histórico-museológica, a pesquisa científica desenvolvida na FSJ para o projeto que pleiteia sua requalificação estrutural e social, lançou mão de uma abordagem integrativa, buscando contemplar as múltiplas dimensões da relação que se estabelece entre as pessoas que a frequentam e/ou que nela comercializam, contribuindo para uma análise holística dos processos e elementos da diversidade cultural que constroem e reconstroem a sua identidade.

Outro importante item de identidade cultural, o azeite de dendê, talvez a principal imagem referencial do estado da Bahia, também conhecido como o ouro de Iansã, é também um produto muito comercializado na Feira de São Joaquim. Uma das matérias-primas do tradicional bolinho de feijão baiano, o azeite de dendê é produzido na região do recôncavo e, em muitos rodões (casa de extração do azeite de dendê), na cidade de Valença, ainda se preserva a forma artesanal de produção.

As farinhas, típicas na culinária brasileira e apreciadas em toda a região nordeste, também podem ser adquiridas em diversos pontos de venda na Feira. Em suas diversas tipologias, sendo a mais procurada a famosa farinha copioba, as farinhas se diferenciam pelo modo de produção.

Com feito, a farinha copioba merece uma atenção especial, em função da sua complexa e peculiar forma de produção. Todo o processo é feito em uma casa de farinha tradicional, localizada na Fazenda Copioba (daí o nome da farinha), no município de Nazaré, região do Baixo Sul baiano, de responsabilidade da família do senhor Antônio de Veríssimo. Seus saberes e fazeres relacionados à produção da farinha copioba (ou farinha de copioba), um bem cultural que constitui um traço marcante da identidade cultural baiana, estão em situação de risco, uma vez que este senhor está 
idoso e não tem perspectiva de transmitir essa tradição para gerações posteriores. Além de todas essas especificidades, diferentemente das outras farinhas, a farinha copioba não passa por um processo de torrefação e sim de secagem, e não recebe nenhum tipo de corante artificial, o que lhe confere sabor e coloração singulares.

Outro elemento identitário brasileiro, a pimenta, também tem seu espaço na FSJ. As tipologias de pimenta, na feira, são inúmeras e com os mais curiosos nomes: malagueta (e seu subtipo, a malaguetinha), pimenta-do-reino, pimenta cominho, pimenta-de-cheiro, arriba-saia-de-moça, cumarim, pimenta calabresa, páprica, pimentão, dedo-demoça, são apenas algumas das centenas de variações dessa especiaria que pode ser facilmente encontrada na Feira, além das receitas de conserva e de molhos que os feirantes frequentemente ensinam aos seus clientes.

É digno de nota o estabelecimento das relações entre consumidor e comerciante que ultrapassam o aspecto comercial-mercadológico. A título de exemplo, observamos que, na Feira, o consumidor que se dirige a um box em que se vende folhas e ervas da fitoterápica popular, não só recebe o produto específico que atende a sua solicitação, como também é informado sobre todo o processo de manuseio e consumo do produto. Algumas vezes, o vendedor dissuade o comprador a optar por um produto mais adequado para as suas necessidades. Em outra circunstância típica, vemos compradores de pimenta cuidadosamente tomando nota das receitas de conserva da especiaria fornecida pelo vendedor.

Religiosos das mais diversas (notadamente, os pertencentes às religiões de matriz cultural africana), comerciantes, estudantes, revendedores, donas de casa, pesquisadores, trabalhadores diversos, turistas, enfim, um público altamente variado e diversificado aflui diariamente para a FSJ.

Principalmente pelos símbolos e signos que a constitui, a FSJ tem um relevante papel na dinâmica processual da identidade cultural afrobrasileira. Nesse lugar, as trocas, as relações, os rituais, os produtos, os saberes e fazeres são caracteres que concorrem para sua legitimação como bem cultural imaterial, não só por parte da comunidade do entorno que estabelece uma intercomunicação geofísica, como também pelo grande público oriundo de diversas partes do Brasil e do mundo que buscam na Feira de São Joaquim os mais variados produtos e serviços.

Não podemos deixar de considerar um aspecto peculiar da Feira de São Joaquim, sob pena de descaracterizarmos: ao tempo que é, em si, um bem cultural, passível de ser patrimonializado, ela também subsidia a manutenção e sustentação de outros bens culturais.

Tão somente a título de exemplificação, podemos com segurança afirmar que é na Feira de São Joaquim que a baiana de acarajé adquire todos os ingredientes e utensílios de que depende seu ofício; é na Feira de São Joaquim que a grande maioria dos grupos de sambadores, sambadeiras e capoeiristas compram cabaças, as contas e outros elementos que compõem a indumentária e o instrumental básico para as suas aulas, celebrações e/ou apresentações; também os famosos colares dos Filhos de Gandhi (mencionados anteriormente), internacionalmente conhecido bloco carnavalesco de tradição afro, são produzidas e comercializadas na Feira de São Joaquim ( em uma única loja, das dezenas que comercializam e produzem esse objetosímbolo de carnaval, pode-se obter cerca de 5 mil unidades desse produto); diversas festas populares do calendário cultural baiano também buscam seus produtos na feira, sem falar do carnaval de Salvador, a maior festa popular do mundo, que durante os cinco dias de folia momesca só encontram na Feira de São Joaquim, em pleno funcionamento, os alimentos, temperos e ingredientes para as comidas e bebidas das famosas feijoadas da elite, camarotes e blocos de trio.

No plano pedagógico das instituições educacionais, em geral, e em todos os níveis, o espaço para as discussões e pesquisas sobre a cultura popular é, somenos, minorado e/ou preterido. Quando existem, ainda são muito tímidas ou incipientes, naquilo que se propõem as iniciativas de trazer à baila as expressões da cultura popular nas disciplinas dos currículos escolares. Não por acaso, em sua grande maioria - para não dizer todas elas - são essas expressões, consubstanciadas pela matriz cultural de origem africana.

A Feira de São Joaquim pode e deve ser explorada pelas escolas, nas mais variadas situações de aprendizado que potencialmente oferecem sem perder de vista o caráter lúdico e a criatividade que impregnam o processo pedagógico arte-educativo, uma vez que encera em si, ao mesmo tempo, as características de espaço e produto da confluência de diversas expressões da cultura.

Fundamentada nos pensamentos de Elliot Eisner e Paulo Freire, Ana Mae assim argumenta sobre a complexidade conceitual da educação: 
A educação é mediatizada pelo mundo em que se vive, formatada pela cultura, influenciada por linguagens, impactada por crenças, clarificada pela necessidade, afetada por valores e moderada pela individualidade. Trata-se de uma experiência com o mundo empírico, com a cultura e a sociedade personalizada pelo processo de gerar significados, pelas leituras pessoais auto-sonorizadas do mundo fenomênico e das 'paisagens anteriores (BARBOSA, 2005, p. 12).

Partindo da premissa estabelecida pelos Parâmetros Curriculares Nacionais para o Ensino Médio, que estabelecem como objeto do ensino da arte "[...] capacitar os estudantes a humanizarem-se melhor como cidadãos inteligentes, sensíveis, estéticos, reflexivos, criativos e responsáveis, no coletivo, por melhores qualidades culturais na vida dos grupos e das cidades, com ética e respeito pela diversidade'(BRASIL, 2000a, p. 50), faz-se necessário o desenvolvimento de práticas pedagógicas nos espaços culturais onde a diversidade cultural se dá de forma profusa e livre, como a FSJ, onde a vida pulsante concorre para a manutenção e ressignificação dos signos e símbolos constitutivos da nossa identidade cultural.

A educação para o patrimônio preconiza a utilização dos bens culturais como recursos educacionais. Sistema de ensino/aprendizado fundamentado nos bens culturais como fonte pedagógica primária.

Os processos pedagógicos dessa tipologia de situação de aprendizado, que se vale do binômio cultura/educação na valorização do ser humano, fundamentam-se na busca da cidadania cultural, na qual o indivíduo tem contato, analisa, entende e apreende as expressões culturais do seu tecido social, o que lhe possibilita exercer seu criticismo e responsabilidade pelo patrimônio cultural, discutindo o seu uso e se apropriando do seu espaço em sociedade enquanto ator e autor desse fenômeno em constante reformulação que é a cultura.

A preservação de um bem precede o reconhecimento do valor desse bem, esse reconhecimento, por seu turno, requer um contato e uma apreensão desse bem. Assim, se dá com o patrimônio cultural e a pedagogia patrimonial oferece todos os mecanismos e estratégias que provocam o contato estreito com a cultura, o estudo aprofundado dos seus usos e significados e, por fim, a valorização para a preservação enquanto documento identitário.

\section{Notas}

1 Referência ao Recôncavo Baiano, região do estado da Bahia cuja área se localiza em torno da Baía de Todos os Santos. A região do Recôncavo Baiano é composta por 33 municípios, tendo no seu limite norte a capital do estado da Bahia.

2 Feira de Água de Meninos é outra denominação pela qual é conhecida a Feira de São Joaquim. Igualmente, "Água de Meninos" é como a população soteropolitana se refere à região na qual está localizada a Feira de São Joaquim.

3 Para falarmos em fruição cultural apropriamo-nos, aqui, do conceito de fruição utilizado por Ana Viale Moutinho (2001) defende que a noção de fruição de uma peça, está implícito que o seu espectador ou utilizador vai compreendê-la, perceber para que é que ela serve e, por fim, tirar partido dela, no sentido de gostar ou não dela.

4 Patrimônio Imaterial: O Registro do Patrimônio Imaterial: Dossiê final das atividades da Comissão e do Grupo de Trabalho Patrimônio Imaterial. Brasília: Ministério da Cultura /Instituto do Patrimônio Histórico e Artístico Nacional, 4. ed. 2006, p. 128.

5 Decreto que institui o Registro de Bens Culturais de Natureza Imaterial que constituem patrimônio cultural brasileiro, cria o Programa Nacional do Patrimônio Imaterial e dá outras providências.

6 Disponível no site http://www.revistamuseu.com. br/18demaio/artigos.asp?id=3989, acessado em 05 de abril de 2016.

7 A Feijoada dos Feirantes e o Caruru dos Feirantes são almoços coletivos promovido pelos comerciantes da feira de São Joaquim, que se organizam entre si para o custeio e todos os preparativos. São encontros festivos protagonizados por religiosos de matriz cultural afrobrasileira. A despeito de haver participação de parentes e amigos desses feirantes o grande público não participa de tais eventos que são feitos pelos feirantes para os feirantes.

8 As chamadas "lavagens" ou "festas de largo" são festas católicas cujo clímax é a lavagem da escadaria da igreja consagrada a um determinado santo católico, no caso citado. As festas em louvor ao Senhor do Bonfim, Conceição da Praia e Bom Jesus dos Navegantes dialogam com a Feira de São Joaquim, que está inserida no espaço físico da festa seja por mar ou por terra.

9 O conceito de lugar referido neste texto baseia-se na proposta de Augé (1994) que problematiza a definição e a percepção de novos espaços 
interpretada a partir da abordagem da supermodernidade.

\section{Referências}

AUGÈ, M. Não-Lugares: Introdução a uma antropologia de super-modernidade. Campinas: Editora Papirus, 1994.

BARBOSA, A. M. Arte/Educação contemporânea. São Paulo: Cortez, 2005.

BENJAMIN, W. Experiência e pobreza. In: .Magia e técnica, arte e política: ensaios sobre literatura e história da cultura. Obras escolhidas v. 1. $8^{\text {a }}$ ed., Revista. São Paulo: Brasiliense, 2012.

BENJAMIN, W. O Narrador - considerações sobre a obra de Nikolai Leskov. In: ___ Magia e técnica, arte e política. São Paulo: Brasiliense, 1985.

BRASIL. Ministério da Cultura. Política Nacional de Museus: memória e cidadania. Brasília: MinC, 2003.

BRASIL. Patrimônio Imaterial: O Registro do
Patrimônio Imaterial: Dossiê final das atividades da Comissão e do Grupo de Trabalho Patrimônio Imaterial. Brasília: Ministério da Cultura /Instituto do Patrimônio Histórico e Artístico Nacional, 4. ed. 2006. p. 128.

BRASIL. Decreto ${ }^{\circ} 3.551$ de 4 de agosto de 2000 .

COSTA, H. H. F. G. C. Um Patrimônio Comum a Todos. Revista Museu. Disponível em: $<$ http://www.revistamuseu.com.br/18demaio/artigos .asp?id=3989>. Acesso em: 05 de abril/2016.

MOUTINHO, A. V. 2001. "Tirar prazer da obra de Arte?". Mealibra - Revista de Cultura, v. 9, p. 227228, 2001.

MOTT, L. R. B. A Feira de Brejo Grande: um estudo de uma instituição econômica num município sergipano do baixo São Francisco, 1975. 348 f. Tese (Doutorado em Ciências Sociais) Universidade de Campinas, Campinas/SP, 1975

SANTOS, M. C. $O$ dinamismo urbano e suas implicações regionais: o exemplo de Santo Antônio de Jesus. Salvador: Editora UNEB, 2002. 106 p.

UNESCO. Convenção para a salvaguarda do patrimônio cultural imaterial. Paris, 17 de outubro de 2003.

\section{Sobre os autores}

Valdemar de Assis Lima é Mestrando em Educação e Professor auxiliar da Universidade Federal de Santa Catarina. Graduado em Museologia pela Universidade Federal da Bahia Universidade Federal do Espírito Santo.

Elison Antonio Paim é Professor Adjunto e Coordenador do Programa de Pós-Graduação em Educação da Universidade Federal de Santa Catarina. Doutor em Educação pela Universidade Estadual de Campinas, mestre em História pela Pontifícia Universidade Católica de São Paulo e graduado em História pela Universidade Federal de Santa Maria.

Recebido em dezembro de 2016. Aprovado em março de 2017. 